\title{
On the Seasonality of the EI Niño Teleconnection to the Amundsen Sea Region $\mathscr{O}$
}

\author{
Yu YeUng SCOTT Yiu AND AmANDA C. MAYCOCK ${ }^{\mathrm{a}}$ \\ Centre for Atmospheric Sciences, Department of Chemistry, University of Cambridge, Cambridge, United Kingdom
}

(Manuscript received 30 November 2018, in final form 26 March 2019)

\begin{abstract}
The Amundsen Sea low (ASL) is a quasi-stationary low pressure system that affects climate in West Antarctica. Previous studies have shown that El Niño-Southern Oscillation (ENSO) modulates the position and strength of the ASL with the strongest teleconnection found in austral winter despite the amplitude of ENSO events generally being largest in austral autumn/summer. This study investigates the mechanisms behind the seasonality of the El Niño teleconnection to the Amundsen Sea region (ASR) using experiments with the HadGEM3 climate model forced with an idealized fixed El Niño sea surface temperature anomaly present throughout the year. The seasonality of the El Niño-ASR teleconnection is found to originate from seasonal differences in the large-scale zonal winds in the South Pacific sector. In austral winter, the region of strong absolute vorticity near $\sim 30^{\circ} \mathrm{S}$ associated with the subtropical jet, in combination with the changes to upper-tropospheric divergence due to the El Niño perturbation, acts as an anomalous Rossby wave source that is largely absent in austral summer. Furthermore, in austral summer the poleward propagation of tropically sourced Rossby waves into the ASR is inhibited by the strong polar front jet in the South Pacific sector, which leads to Rossby wave reflection away from the ASR. In austral winter, Rossby waves are able to propagate into the ASR, forming part of the Pacific South America pattern. The lack of the Rossby wave source in the tropical Pacific and the absence of favorable conditions for wave propagation explains the weaker El Niño-ASR teleconnection in austral summer compared to austral winter.
\end{abstract}

\section{Introduction}

The Amundsen Sea low (ASL) is a quasi-stationary climatological low pressure center found in the South Pacific sector of the Southern Ocean (Turner et al. 2013; Hosking et al. 2013; Raphael et al. 2016). It lies approximately between the Antarctic Peninsula and the Ross Sea and is sometimes called the AmundsenBellingshausen Sea low (Hosking et al. 2013). The ASL is one of three climatological low pressure centers located along the circumpolar trough (Turner et al. 2013) and exhibits the highest variability of circulation in the Southern Hemisphere (Lachlan-Cope et al. 2001).

\footnotetext{
Supplemental information related to this paper is available at the Journals Online website: https://doi.org/10.1175/JCLI-D-180813.s1.

${ }^{a}$ Current affiliation: School of Earth and Environment, University of Leeds, Leeds, United Kingdom.
}

Corresponding author: Amanda C. Maycock, a.c.maycock@ leeds.ac.uk
The existence of the ASL is associated with the zonal asymmetry of tropical sea surface temperatures (SSTs), which generates planetary-scale Rossby waves that contribute to zonal asymmetry in the Southern Hemisphere storm track (Inatsu and Hoskins 2004). The Southern Hemisphere storm tracks are important for the ASL since this feature can be interpreted as the time average over the large number of synoptic- and subsynoptic-scale cyclonic systems that propagate through the Amundsen Sea region (ASR) (Fogt et al. 2012). The unique topography and geography of Antarctica also play an important role in the enhanced baroclinicity needed for the formation of synoptic systems in the circumpolar trough (Walsh et al. 2000; Lachlan-Cope et al. 2001; Hosking et al. 2013).

The ASL exhibits a pronounced annual cycle in both its location and depth (Fogt et al. 2012; Hosking et al. 2013; Turner et al. 2013). On average, the ASL depth is greatest during austral winter (JJA) and weakest during austral summer (DJF) (Hosking et al. 2013). Additionally, the center of the ASL tends to be located farther eastward and northward in austral summer and more westward and southward in austral winter (Fogt et al. 2012; Hosking et al. 2013; Turner et al. 2013). The climate in West Antarctica is greatly affected by the ASL (Raphael et al. 
2016; Turner et al. 2013; Hosking et al. 2013). Hosking et al. (2013) found that both the longitude and strength of the ASL play a role in determining surface winds, temperature, precipitation, and sea ice concentrations near West Antarctica. These relationships are complex and are often seasonally dependent. Other studies, such as those of Turner et al. $(2009,2016)$, have linked changes in the location and depth of the ASL to recent Antarctic sea ice changes. It is therefore important to understand the factors that affect the ASL on interannual and longer time scales.

One known driver of the ASL is El Niño-Southern Oscillation (ENSO) (Hoskins and Karoly 1981; Karoly 1989; Chen et al. 1996; Liu et al. 2002; Turner 2004; Lachlan-Cope and Connolley 2006). Turner et al. (2013) and Clem et al. (2017) found that during El Niño, the mean ASL pressure was anomalously high, and vice versa during La Niña. The ASL was also found to be located farther southeast during El Niño and farther northwest during La Niña (Clem et al. 2017). These findings are mostly consistent with previous studies by Bertler et al. (2004) but are in disagreement with Kreutz et al. (2000), who found a deepening of the ASL during El Niño using a glaciochemical record from West Antarctica. Another factor influencing climate in West Antarctica is the southern annular mode (SAM) (Marshall 2003; Thompson et al. 2011; Abram et al. 2014), which is also affected by ENSO (L'Heureux and Thompson 2006; Fogt and Bromwich 2006) and by other drivers such as the ozone hole (Thompson and Solomon 2002; Gillett and Thompson 2003; Keeble et al. 2014). Fogt et al. (2011) investigated the combined effects of ENSO and SAM on climate over West Antarctica. They found that strong teleconnections only occur for the case of El Niño and a negative phase of the SAM when the two effects constructively interfere. For El Niño and a positive phase of the SAM, the teleconnections were reduced as the effects destructively interfere (Fogt et al. 2011). However, in some cases when ENSO and SAM are out of phase the teleconnection to the ASR may still be strong in some seasons albeit altered (Clem and Fogt 2013).

Several mechanisms have been proposed to explain the ENSO teleconnection to the ASR. One mechanism is via its influence on the Pacific-South American (PSA) pattern. It was shown by Hoskins and Karoly (1981) and Karoly (1989) that the PSA can be interpreted as a tropically forced Rossby wave train emanating from the tropical Pacific and propagating through the ASR. Schneider et al. (2012) showed that regression of Southern Hemisphere atmospheric circulation onto an ENSO index reveals a strong PSA pattern. Furthermore, Li et al. (2015) showed that changes in tropical east Pacific SSTs cause circulation changes, which create a Rossby wave source (RWS) anomaly that initiates a wave train propagating to high latitudes.
Another proposed mechanism for the ENSO teleconnection to high southern latitudes via its effect on the SAM (L'Heureux and Thompson 2006; Fogt and Bromwich 2006; Gong et al. 2010; Fogt et al. 2011; Schneider et al. 2012; Gong et al. 2013). According to Schneider et al. (2012), there is a distinct seasonality for this mechanism which is strongest in austral summer. The reasons for this have not been fully explored, but could be due to the increased amplitude of ENSO tropical heating during austral summer (L'Heureux and Thompson 2006). However, it could also be due to seasonal characteristics of the large-scale zonal circulation in the Southern Hemisphere (Jin and Kirtman 2009; Schneider et al. 2012). Gong et al. (2013) found in a reduced complexity model that an imposed zonally symmetric heating in the tropics caused the subtropical jet to strengthen and the eddy-driven jet to weaken. The changes in background mean flow caused stronger anticyclonic wave breaking on the equatorward side of the eddy-driven jet (Gong et al. 2010), leading to a negative SAM response to El Niño. The proposed teleconnection via the SAM is related to the studies of Chen et al. (1996), Liu et al. (2002), and Yuan (2004) who suggested a mechanism in terms of the Hadley and Ferrel cells. They proposed that El Niño would intensify the Hadley cell and strengthen and contract the subtropical jet (STJ). This was associated with a contraction of the storm track and a reduction in the number of synoptic and subsynoptic low pressure systems that pass through the ASR, which leads to a weakening of the ASL under El Niño conditions.

A notable feature of the ENSO teleconnection to the ASL is its seasonal variation. Turner et al. (2013) found that the sea level pressure (SLP) anomaly in the ASL between the two phases of ENSO was minimum during austral autumn (MAM) and maximum during austral winter (JJA) despite the fact that ENSO events tend to peak in austral late spring/early summer (NovemberDecember). The correlation of near-surface temperature in the ASR with ENSO was found to be largest in austral winter and autumn and lowest (or even reversed) in austral spring and summer (Bertler et al. 2004). Jin and Kirtman (2009) found in a reanalysis dataset that the maximum Southern Hemisphere response to ENSO occurs in austral spring. Their explanation was that the anomalous Rossby wave source induced by ENSO peaks around one season before ENSO itself peaks (Jin and Kirtman 2009) owing to local seasonality in the Southern Hemisphere circulation.

While the studies discussed above have developed some understanding of the dynamical factors that cause seasonality in tropical teleconnection to the ASR, a detailed assessment of the factors that determine the 
response of the ASL to ENSO and their seasonality has so far been lacking. This topic forms the focus of our study. In particular, we aim to investigate the mechanisms that determine the seasonality of the teleconnection to the ASL using model perturbation experiments with an idealized fixed El Niño SST anomaly imposed throughout the year. This extends previous work (e.g., Jin and Kirtman 2009, 2010) by removing the intrinsic seasonality of ENSO to isolate the effects of the atmospheric seasonal cycle on the teleconnection. Our study is structured as follows: Section 2 describes the climate model used to perform our experiments and the diagnostic tools used in the study, section 3 presents the results of our experiments, and section 4 gives conclusions and presents a mechanistic flowchart that summarizes the findings.

\section{Data and methods}

\section{a. Model description}

Experiments are performed using the Hadley Centre Global Environment Model version 3 (HadGEM3). The configuration used is the UM version 8.4 Global Atmosphere (GA) 4.0 with N96 $\left(1.875^{\circ}\right.$ longitude $\times 1.25^{\circ}$ latitude) horizontal resolution and 85 vertical levels up to an altitude of $\sim 84 \mathrm{~km}$ (Walters et al. 2014). The model is run in an atmosphere-only configuration with reference SSTs and sea ice prescribed from the HadISST dataset (Rayner et al. 2003).

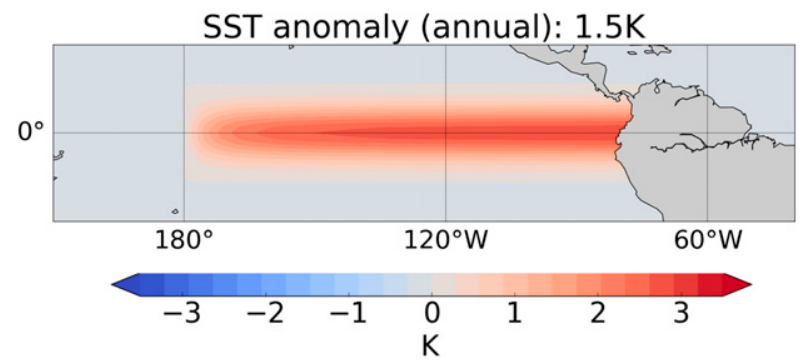

FIG. 1. The SST anomaly imposed in the El Niño experiment, which is held constant year round.

\section{b. Experimental setup}

Idealized time-slice experiments were performed to investigate the seasonality of the ENSO-ASR teleconnection. The control simulation uses monthlyvarying SSTs and sea ice averaged from 1995 to 2005 to represent year 2000 climatological (ENSO neutral) conditions. All other boundary conditions (greenhouse gases, aerosols) represent year 2000 conditions and are kept fixed in all experiments.

A perturbation experiment is performed with imposed SST anomalies in the tropical Pacific. The SST perturbation is designed to capture the broad pattern of a classical east Pacific El Niño. The pattern of SST anomalies $(\delta T)$ is defined according to the following function:

$$
\delta T(\lambda, \phi)=\left\{\begin{array}{ll}
\alpha \times \tan ^{-1}[(\lambda-180) / 6] \times \exp \left[-0.03\left(\phi^{2}\right)\right], & \text { if } 180^{\circ} \leq \lambda \leq 285^{\circ} \\
0, & \text { otherwise },
\end{array} \text { and }-10^{\circ} \leq \phi \leq 10^{\circ},\right.
$$

where $\alpha$ is a scaling factor and the other nomenclature is standard. In the El Niño experiment $\alpha$ is set to 1.15 corresponding to a Niño-3.4 index anomaly of $1.5 \mathrm{~K}$. The pattern of SST anomalies produced by this function is shown in Fig. 1.

The imposed SST anomalies are held fixed in time, which is unrealistic as real El Niño events exhibit a clear seasonal evolution. Nevertheless, this experimental design allows us to systematically explore the mechanisms for the seasonality of the El Niño teleconnection for a fixed tropical SST forcing. This approach allows us to overcome some of the limitations of the observational record in which each El Niño event has a different structure, magnitude, and temporal evolution, thereby rendering it difficult to distinguish the factors that contribute to the seasonality in the teleconnection to the ASR.

Both the control and perturbed time-slice experiments are 54 years long. The experiments analyzed here are a subset of those described by Trascasa-Castro et al. (2019). All anomalies in this study refer to the difference between the El Niño and the control experiment unless otherwise specified.

\section{c. Calculation of the Rossby wave source}

Following Sardeshmukh and Hoskins (1988), the RWS $S$ is given by

$$
S=-\zeta D-v_{\chi_{x}} \nabla \zeta_{x}-v_{\chi_{y}} \nabla \zeta_{y},
$$

where $\zeta$ is the absolute vorticity, $D$ is the divergence of the horizontal wind, $v_{\chi_{x}}$ is the $x$ component of the divergent wind, and $v_{\chi_{v}}$ is the $y$ component of the divergent wind. The first term $(\zeta D)$ represents the rate of change of vorticity due to vortex stretching and the second $\left(v_{\chi_{x}} \nabla \zeta_{x}\right)$ and third $\left(v_{\chi_{y}} \nabla \zeta_{y}\right)$ terms represent the rate of change of vorticity due to vorticity advection by the 
horizontal and meridional components of the divergent wind, respectively.

The rationale behind the RWS is that even though the divergent flow is only a small part of total horizontal flow, the vorticity associated with it is extremely important for understanding tropical-extratropical interactions on longer than synoptic time scales. Sardeshmukh and Hoskins (1988) found that a heating in the equator can cause a nonlocal "effective Rossby wave source" to appear in the subtropical westerly jets, which plays a key role in explaining the existence of strong tropical-extratropical teleconnections.

\section{d. Rossby wave ray tracing and wave activity flux}

Rossby wave ray tracing was developed by Hoskins and Karoly (1981) and Karoly and Hoskins (1982) and provides insight to how the background climatological state impacts the propagation of a linear Rossby wave. While ray tracing typically relies on several simplifying assumptions (see below), linear wave theory has been shown to apply well in many situations (Hoskins and Karoly 1981; Karoly and Hoskins 1982; Li et al. 2015; Scaife et al. 2017). The theory for ray tracing shown below follows Hoskins and Karoly (1981), Karoly and Hoskins (1982), and Hoskins and Ambrizzi (1993). For simplicity, the equations will be presented in Cartesian coordinates. We start with the simplest case of a linear, barotropic Rossby wave dispersion relation with no background meridional flow:

$$
\omega=U k-\frac{\beta^{*} k}{K^{2}}
$$

where $\omega$ is the frequency, $U$ is the zonal wind, $\beta^{*}$ is the meridional gradient in absolute vorticity, $K$ is the total wavenumber $\left(K=\sqrt{l^{2}+k^{2}}\right), k$ is the zonal wavenumber, and $l$ is the meridional wavenumber.

The typical time scale for Rossby waves to propagate from the tropics to the extratropics is around 1-2 weeks (Jin and Hoskins 1995). Hence for our purposes, where we are examining signals on seasonal time scales, the propagation time scale is relatively short and we therefore consider the case of stationary waves where $\omega=0$. In this case Eq. (3) can be rewritten as

$$
K^{2}=\frac{\beta^{*}}{U} \text {. }
$$

Note that the wave train evolves according to the propagation of wave energy (given by the group velocity). The group velocities of the waves are

$$
c_{g x}=\frac{\partial \omega}{\partial k}=\frac{2 \beta^{*} k^{2}}{K^{2}}, \text { and }
$$

$$
c_{g y}=\frac{\partial \omega}{\partial l}=\frac{2 \beta^{*} k l}{K^{2}},
$$

where $c_{g x}$ is the group velocity in the $x$ direction and $c_{g y}$ is the group velocity in the $y$ direction. Thus the direction of propagation of the wave front can be found by dividing Eq. (5) by Eq. (6) to give

$$
\frac{d x}{d y}=\frac{c_{g x}}{c_{g y}}=\frac{k}{l} .
$$

Using $K=\sqrt{l^{2}+k^{2}}$ and Eq. (4), we can rewrite Eq. (7) to give

$$
\frac{d x}{d y}=\frac{k}{\sqrt{\frac{\beta^{*}}{U}-k^{2}}} .
$$

Thus the angle $\left[\tan ^{-1}(d y / d x)\right]$ of the Rossby wave ray can be computed for any given $k$. Equation (8) can be used to trace the theoretical path of a Rossby wave. Note that $l$ controls the meridional direction of the rays. Here this is set to -1 (southward propagating) as our work is concerned with wave propagation into the Southern Hemisphere.

There are three possibilities for a ray at any point during its propagation: it can propagate, reflect, or evanesce. For $\beta^{*} / U<k^{2}$ [i.e., when the denominator in Eq. (8) is imaginary] the waves are reflected. For $U<0$ (i.e., easterly winds) the waves are evanescent. If the wave is neither reflected nor terminated at a given point, it will propagate in the direction given by Eq. (8).

The derivation of Eq. (8) relies on several simplifying assumptions. First, the WKBJ approximation is used, which assumes that variations in the background flow are slow relative to the variations associated with the wave. As discussed in Hoskins and Karoly (1981) and Li et al. (2015), this assumption holds well for small-scale waves, but may not be as applicable for planetary-scale waves. Second, Eq. (3) is only valid for the case of purely zonal flow. However, for realistic meridional flows the equation can only be used as an approximation if the zonal gradients of the absolute vorticity are small relative to the meridional gradient of absolute vorticity. Since the background large-scale flow is organized into zonal jets, the zonal vorticity gradients are usually small compared to the meridional gradient. While Li et al. (2015) suggested that one such exception may be located in the east Pacific (our area of interest), our analysis of HadGEM3 shows that the meridional vorticity gradient in this area is larger than the zonal gradient.

Following Li et al. (2015), ray tracing is performed here using a zonal wavenumber of $k=3$. However, sensitivity 


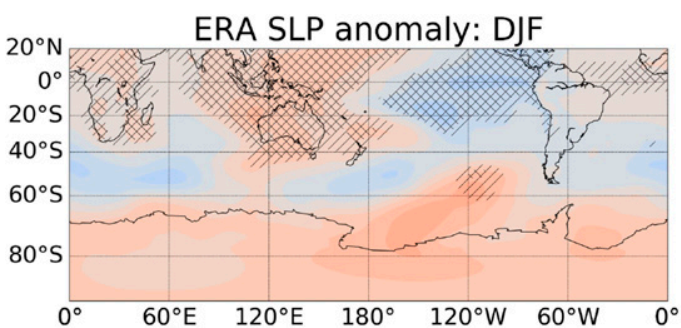

(a)

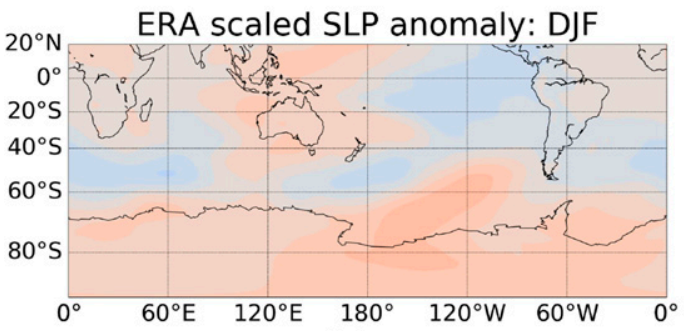

(c)

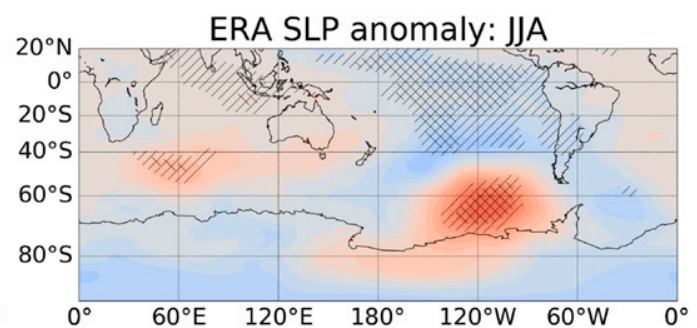

(b)

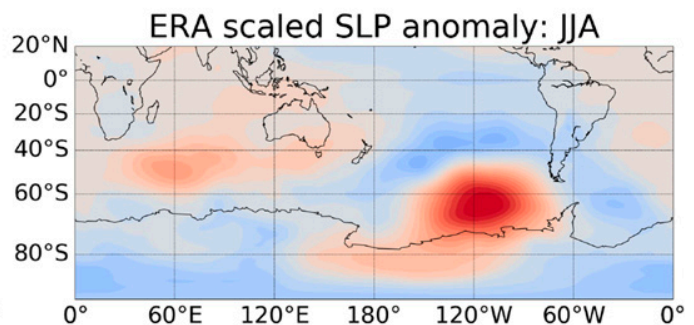

(d)

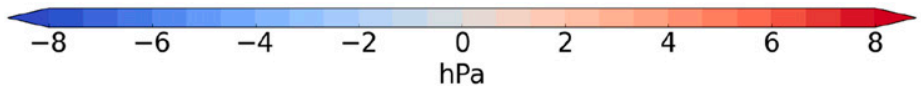

FIG. 2. Composite SLP anomalies (hPa) under El Niño conditions in (a),(b) ERA-Interim and (c),(d) ERAInterim scaled to a seasonal mean ONI index of $1.5 \mathrm{~K}$. Single hatching in (a) and (b) shows regions of $95 \%$ significance while double hatching shows $99 \%$ significance. Statistical significance is calculated using a two-tailed Student's $t$ test. Hatching is not shown in the lower panels as these are scaled from the upper panels.

tests were carried out using $k=1,2,4$, and 5 . These tests showed only small differences in the paths of the rays and the overall picture was unchanged. Additionally, following Li et al. (2015), a 2D Gaussian filter is applied to the $\beta^{*}$ and $U$ fields before the ray tracing is performed. This is because the Rossby waves (at $k=3$ ) are large compared to the model grid scale and hence their propagation will not be affected by small scale features in the background vorticity and wind fields. The Gaussian filter is set to a radius of $15^{\circ}$, but the results are not found to be sensitive to the exact scale of filter chosen.

Note that while climatological seasonal mean fields are used here for the ray tracing calculations, a further test was conducted in which ray tracing was performed for every individual season before summation. The results were found to be similar between these approaches and for simplicity we present here ray tracing results using the 54-yr climatology from the El Niño experiment.

In addition to the RWS and ray tracing calculations, we also compute the wave activity flux following Plumb (1985). This combines information about the wave sources and wave propagation to give an overall quantitative picture of wave energy fluxes. Both the ray tracing and wave flux analysis provide useful information to understand and interpret teleconnection responses and thus both techniques are employed in our work. Note that here we will only deal with the 2D horizontal wave flux. This is because the flux in the vertical direction is usually much smaller compared with that in the horizontal direction (see Plumb 1985) and because we are primarily concerned with horizontal wave propagation. The $2 \mathrm{D}$ wave flux analysis is applied in the upper troposphere, since this is the region of strong divergence from convective motions, which coincide with the peak RWS (e.g., Scaife et al. 2017).

Following Plumb (1985), the 2D wave activity flux is given by

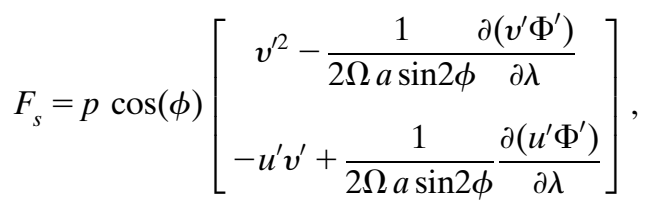

where the primes denote deviations from the zonal mean, $p$ is pressure divided by $1000 \mathrm{hPa}, u$ is zonal wind, $v$ is the meridional wind, $\Omega$ is Earth's rotation rate, $a$ is the radius of the Earth, $\phi$ is latitude, $\Phi$ is geopotential, and $\lambda$ is longitude. 


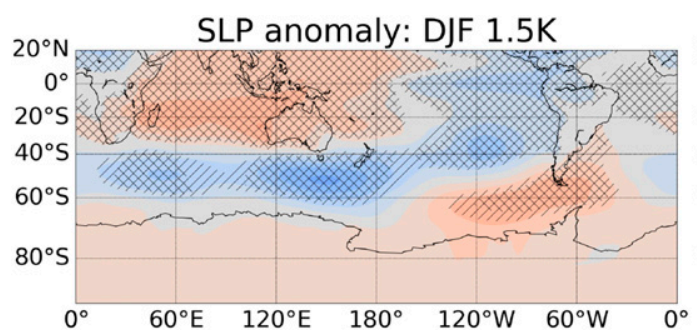

(a)

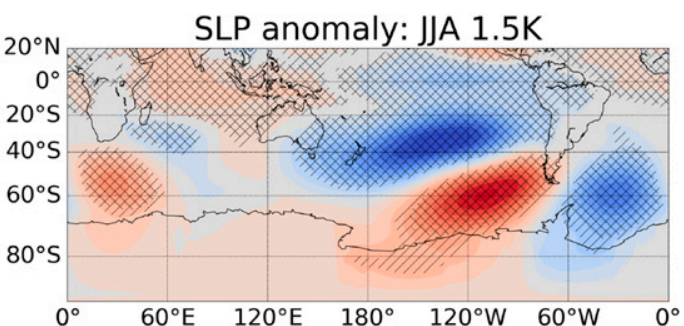

(b)

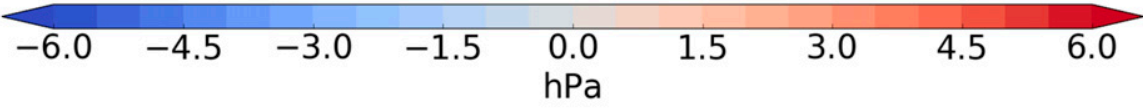

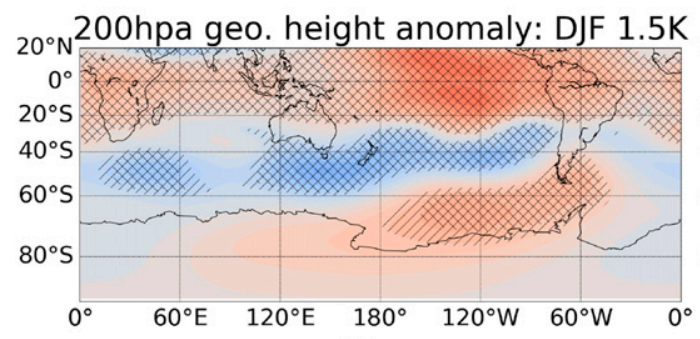

(c)

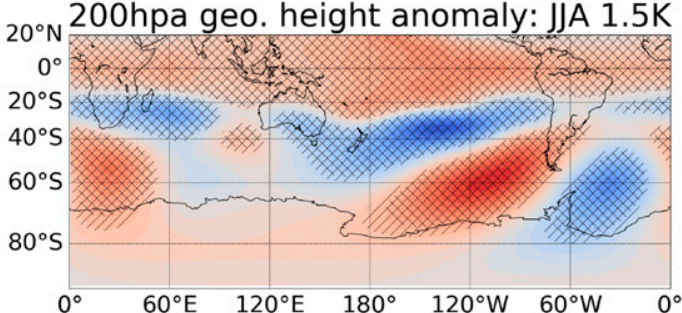

(d)

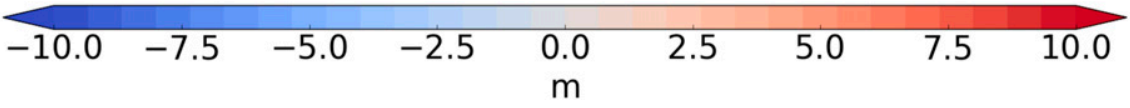

FIG. 3. Seasonal mean SLP anomalies (hPa) in the El Niño experiment for (a) DJF and (b) JJA. Also shown are seasonal mean 200-hPa geopotential height anomalies (m) for (c) DJF and (d) JJA in the El Niño experiment. Single hatching shows regions of $95 \%$ significance while double hatching shows $99 \%$ significance.

\section{Results}

\section{a. Amundsen Sea region response to El Niño}

Before investigating the El Niño perturbation in the model simulations, we first examine the impact of El Niño on the ASR in the ERA-Interim reanalysis dataset (Dee et al. 2011). We define observed El Niño years to have an Oceanic Niño Index (ONI) in DJF of $>1.0 \mathrm{~K}$. Years with a $-1.0 \mathrm{~K}<\mathrm{ONI} \leq 1.0 \mathrm{~K}$ in DJF are considered to be ENSO neutral years. While this is higher than the conventional threshold for El Niño events (usually around ONI $\geq 0.5 \mathrm{~K}$ ), the ONI in JJA will be significantly lower than DJF as El Niño events tend to peak in November-December. Therefore, a higher threshold of the ONI is used to capture the strongest El Niño events that also give a reasonable ONI anomaly in JJA. This definition captures 8 El Niño events and 25 ENSO neutral years over the period 1979-2016 with a composite Niño3.4 temperature anomaly for El Niño of $\sim 1.8 \mathrm{~K}$ in DJF and $\sim 1.0 \mathrm{~K}$ in JJA.

Figures $2 \mathrm{a}$ and $2 \mathrm{~b}$ show the ERA-Interim composite seasonal average sea level pressure (SLP) anomalies between El Niño and ENSO neutral years for DJF and JJA, respectively. Consistent with earlier studies (e.g., Turner et al. 2013; Jin and Kirtman 2010), this shows that DJF exhibits a weaker SLP anomaly over the ASR during El Niño compared with JJA. To facilitate a clearer comparison between the two seasons, Figs. 2c and $2 \mathrm{~d}$ show the ERA-Interim SLP composite anomalies linearly scaled to represent a $1.5-\mathrm{K}$ Niño-3.4 temperature anomaly in both seasons. The scaled SLP anomalies show an even greater difference in the highlatitude response between the two seasons than the raw anomalies, owing to the larger amplitude of observed El Niño events in austral summer. In addition to differences in magnitude, there are marked differences in the structure of the SLP anomalies between the seasons. In JJA, an alternating pattern of negative-positivenegative SLP anomalies can be seen extending from approximately $30^{\circ} \mathrm{S}, 110^{\circ} \mathrm{W}$ toward the ASR and into the Weddell Sea. Conversely, the SLP anomalies in DJF are more zonally symmetric and envelop the whole of Antarctica with a weak maximum located around the ASR. DJF resembles a SAM-like pattern, which may hint 


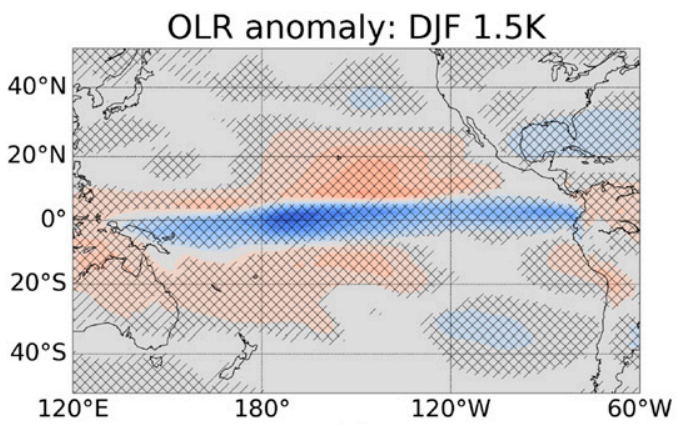

(a)

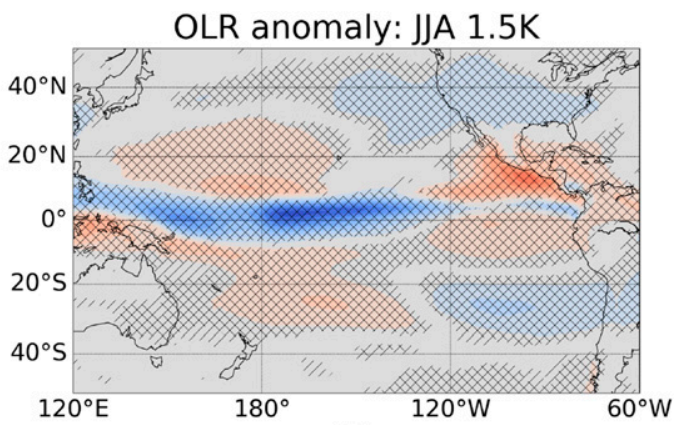

(b)

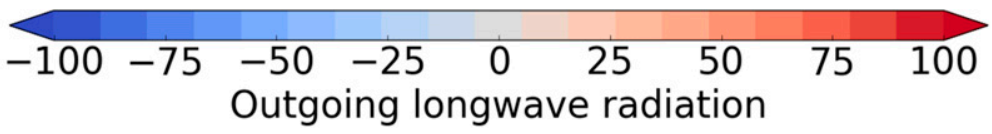

FIG. 4. Pacific sector seasonal mean outgoing longwave radiation anomalies $\left(\mathrm{W} \mathrm{m}^{-2}\right)$ in the El Niño experiment for (a) DJF and (b) JJA. Single hatching shows regions of $95 \%$ significance while double hatching shows $99 \%$ significance.

at different teleconnection mechanisms between the two seasons. These differences in structure are consistent with the results of Ciasto et al. (2015) who also found that east Pacific SST anomalies cause a SAM-like response in DJF and a wave train-like response in JJA. The pattern correlation between the SLP anomalies over the region $30^{\circ}-$ $90^{\circ} \mathrm{S}$ in DJF and JJA is 0.43 . In the transition seasons, the response in MAM also resembles the PSA, but in SON it resembles a negative SAM (see Fig. S1 in the online supplemental material).

The SLP and 200-hPa geopotential height anomalies in the HadGEM3 1.5-K El Niño experiments for DJF and JJA are shown in Figs. $3 \mathrm{a}$ and $3 \mathrm{~b}$ and Figs. $3 \mathrm{c}$ and $3 \mathrm{~d}$, respectively. The model reproduces the pattern and magnitude of anomalies seen in ERA-Interim, with the magnitude and structure showing similar differences between the two seasons. As expected from previous literature, there is a baroclinic response to the tropical heating in the tropics (Gill 1980; Jin and Hoskins 1995) and an equivalent barotropic response in the mid-to-high latitudes (Webster 1981; Simmons et al. 1983; Held and Kang 1987). This is evident from Fig. 3 where the SLP and 200-hPa geopotential height anomalies are negatively correlated in the tropics and positively correlated in the mid-to-high latitudes. Now that we have confirmed that the HadGEM3 model experiment captures the seasonal differences found in the reanalysis dataset, we go on to examine the mechanisms that determine the seasonality of the response to the imposed $\mathrm{El}$ Niño in the ASR.

\section{b. Tropical and subtropical response to El Niño}

Figure 4 shows the anomalous outgoing longwave radiation (OLR) at the top of the atmosphere in the
El Niño experiment for DJF and JJA. Under El Niño, OLR decreases at the equator and increases off-equator to the north and south; this indicates an intensification of the intertropical convergence zone and an eastward shift in the region of strongest convection. However, the changes in OLR due to the imposed El Niño anomaly are broadly similar in both seasons. Similar responses in both seasons are also found for changes in tropical precipitation rates and bulk cloud fraction (not shown), which are other indicators of the structure and intensity of the tropical circulation. Therefore, the differences in the teleconnection to high latitudes between the two seasons are unlikely to be due to the response of tropical convection to the same SST forcing.

Turning to the subtropics, Fig. 5 shows the mass streamfunction in DJF and JJA with the control climatology in contours and the simulated response to the imposed El Niño in shading. The climatological mean meridional circulation is dominated by a strong Hadley cell in the winter hemisphere (e.g., Dima and Wallace 2003). In JJA, when the climatological overturning circulation is strongest in the Southern Hemisphere, the response to El Niño shows an enhancement near the maximum of the cell and a reduction on the equatorial and poleward edges, indicating a strengthening and contraction of the mean meridional circulation. In DJF, when the climatological overturning circulation is strongest in the Northern Hemisphere, the response to El Niño shows similar changes with a strengthening near the maximum and a weakening on the edges of the Hadley cell. These findings are consistent with other studies that have examined the response of the mean meridional circulation to El Niño (e.g., Lu et al. 2008). 


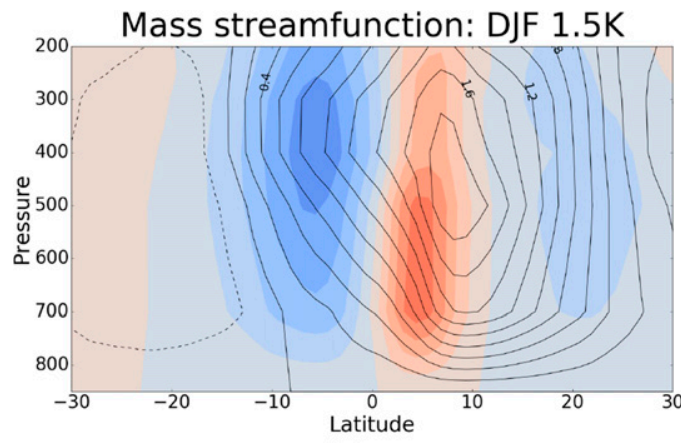

(a)

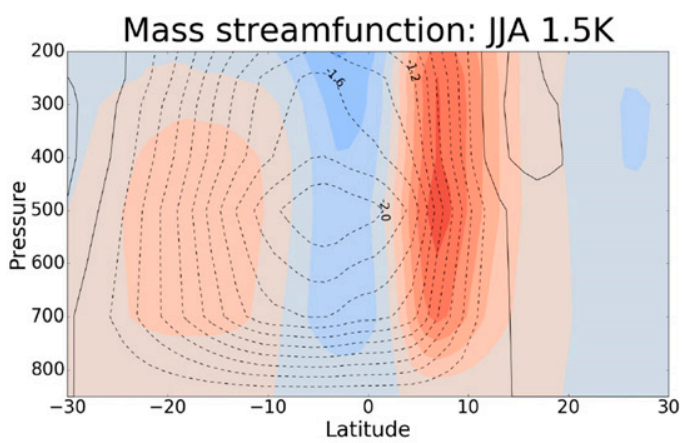

(b)

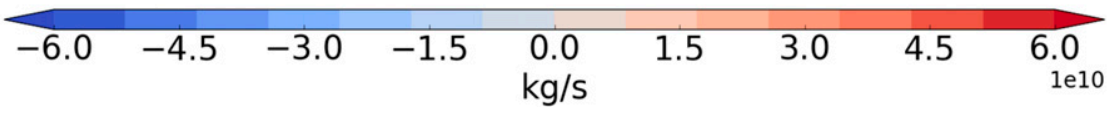

FIG. 5. Seasonal mean mass streamfunction in (a) DJF and (b) JJA. The solid contours show the control climatology $\left(10^{11} \mathrm{~kg} \mathrm{~s}^{-1}\right)$, and the shading shows the anomalies in the El Niño experiment $\left(10^{10} \mathrm{~kg} \mathrm{~s}^{-1}\right)$.

The strengthening and contraction of the Hadley cells is expected to be associated with a strengthening and equatorward shift of the subtropical jet (STJ) (Gallego et al. 2005). Figures $6 \mathrm{a}$ and $6 \mathrm{~b}$ show zonal-mean zonal winds in DJF and JJA with the contours showing the control climatology and the shading the anomalies in the El Niño experiment. In DJF, the climatology is dominated by a strong polar front jet (PFJ) with a maximum wind speed of $\sim 30 \mathrm{~m} \mathrm{~s}^{-1}$ near $50^{\circ} \mathrm{S}$ and $200 \mathrm{hPa}$, while the STJ is relatively weak. Conversely in JJA, there is a

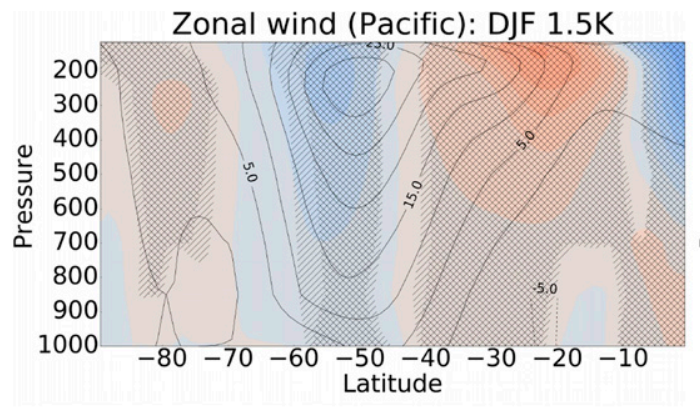

(a)

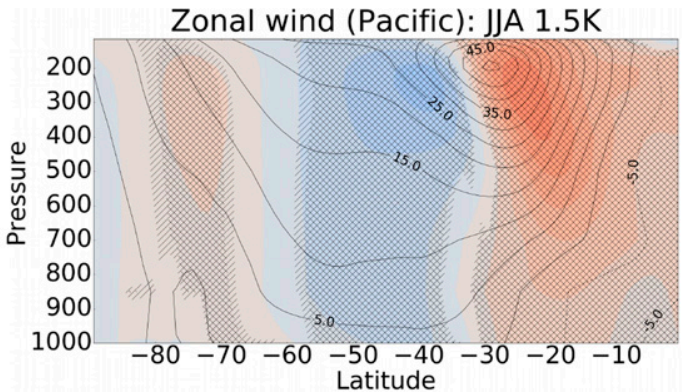

(b)

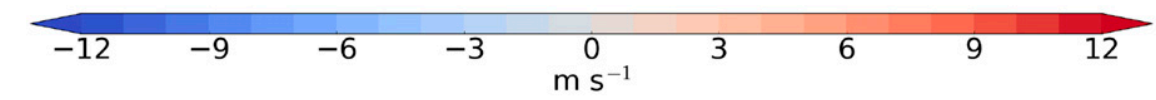

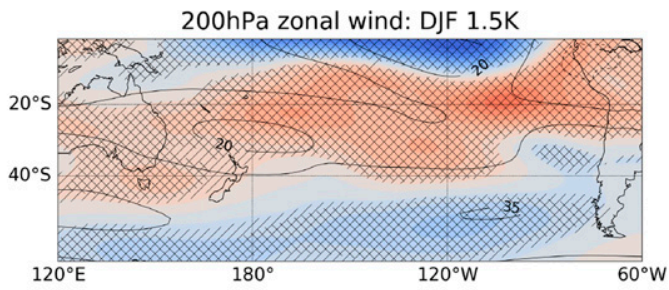

(c)

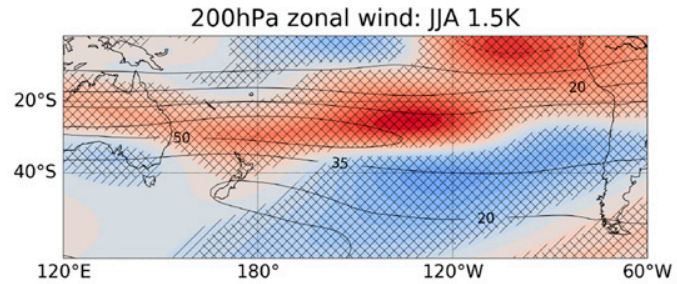

(d)

$$
\begin{array}{lllclll}
-12 & -8 & -4 & \begin{array}{c}
0 \\
\mathrm{~m} \mathrm{~s}^{-1}
\end{array} & 4 & 8 & 12
\end{array}
$$

FIG. 6. (top) Seasonal mean zonal wind $\left(\mathrm{m} \mathrm{s}^{-1}\right)$ averaged over the Pacific sector $\left(120^{\circ} \mathrm{E}-60^{\circ} \mathrm{W}\right)$ in (a) DJF and (b) JJA. The solid contours show the control experiment, and the shading shows the anomalies in the El Niño experiment. (bottom) As in the top panels, but for 200-hPa zonal wind ( $\mathrm{m} \mathrm{s}^{-1}$ ) in the Pacific sector for (c) DJF and (d) JJA. Single hatching shows regions of $95 \%$ significance while double hatching shows $99 \%$ significance. 


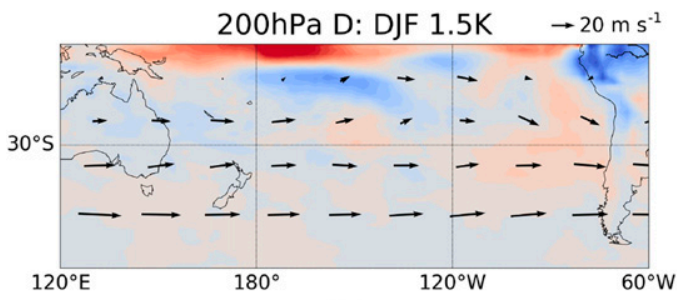

(a)

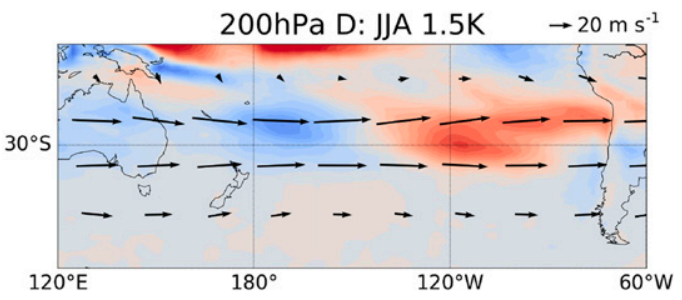

(b)

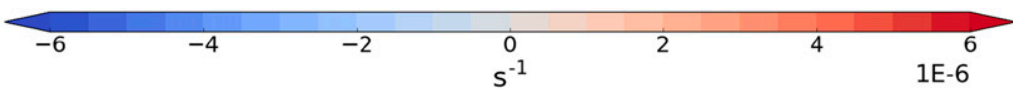

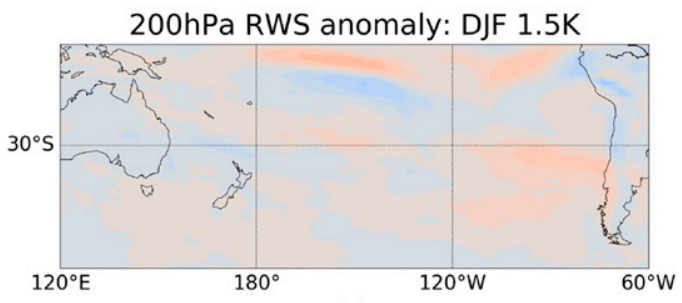

(c)

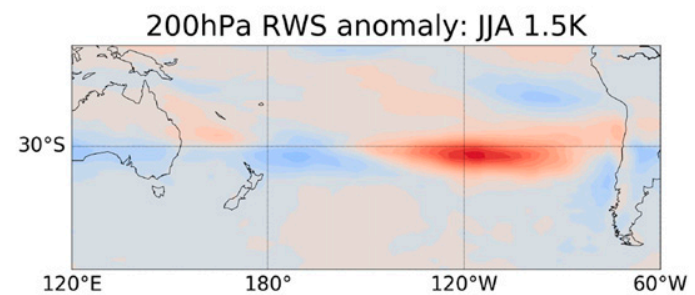

(d)

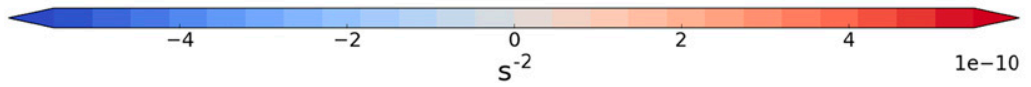

FIG. 7. Seasonal mean anomalies in 200-hPa (top) divergence $\left(\mathrm{s}^{-1}\right)$ and (bottom) RWS ( $\mathrm{s}^{-2}$ ) in (a),(c) DJF and (b),(d) JJA. The RWS is calculated from the 54-yr climatology of each experiment and then differenced. Arrows in (a) show the 200-hPa wind anomaly vectors in the El Niño experiment.

strong STJ with a maximum wind speed of $\sim 50 \mathrm{~m} \mathrm{~s}^{-1}$ near $25^{\circ}-30^{\circ} \mathrm{S}$ and $200 \mathrm{hPa}$, and a second weaker maximum associated with the $\mathrm{PFJ}$ at around $45^{\circ} \mathrm{S}$ and $200 \mathrm{hPa}$ (Galvin 2007; Barnes and Polvani 2013).

In DJF, the zonal-mean zonal wind response in the El Niño experiment shows a positive anomaly in the upper troposphere near the weak STJ maximum around $\sim 25^{\circ} \mathrm{S}$ and $\sim 150 \mathrm{hPa}$. At higher latitudes there is a dipole pattern of zonal wind anomalies extending throughout the troposphere, with a weakening of westerlies on the poleward flank and an increase in westerlies in the equatorward flank of the PFJ. This corresponds to the well-known equatorward shift in the PFJ under El Niño (e.g., Lu et al. 2008; Gallego et al. 2005).

The anomalous zonal-mean zonal winds under El Niño have a different magnitude and structure in JJA compared to DJF. The strongest zonal wind anomalies are in the upper troposphere with a dipole pattern of increased zonal winds on the equatorward flank of the STJ around $\sim 15^{\circ}-20^{\circ} \mathrm{S}$ and decreased zonal winds on the poleward side around $\sim 30^{\circ}-$ $40^{\circ} \mathrm{S}$ (Gallego et al. 2005). The positive anomaly is much stronger in JJA compared with DJF. Furthermore, the negative anomaly that extends throughout the troposphere coincides with the zonal wind maximum in the midlatitude lower troposphere, indicating a weakening of the PFJ in contrast to the jet shift found in DJF.
Figures $6 c$ and $6 \mathrm{~d}$ show the Southern Hemisphere zonal winds at $200 \mathrm{hPa}$ in the Pacific sector. In JJA, the strongest climatological zonal wind speeds are located around $30^{\circ} \mathrm{S}, 90^{\circ} \mathrm{E}-150^{\circ} \mathrm{W}$. Under El Niño conditions, there is a strong positive anomaly approximately located at $30^{\circ} \mathrm{S}, 130^{\circ} \mathrm{W}$ and a negative anomaly at approximately $40^{\circ} \mathrm{S}, 120^{\circ} \mathrm{W}$. This dipole in anomalies is associated with a shift in the maximum zonal wind equatorward and eastward toward the central Pacific. In DJF, the climatological maximum wind speed at $200 \mathrm{hPa}$ is located around $50^{\circ} \mathrm{S}, 50^{\circ} \mathrm{W}-150^{\circ} \mathrm{E}$. In the El Niño experiment, the zonal wind anomalies at $200 \mathrm{hPa}$ in the South Pacific in DJF are weaker and more zonally symmetric compared with JJA.

\section{c. Rossby wave source response to El Niño}

Figures $7 \mathrm{a}$ and $7 \mathrm{~b}$ show seasonal mean anomalies in 200-hPa divergence and Figs. $7 \mathrm{c}$ and $7 \mathrm{~d}$ show differences in RWS at $200 \mathrm{hPa}$ between the El Niño and control experiments calculated using Eq. (2). The arrows in Figs. $7 \mathrm{a}$ and $7 \mathrm{~b}$ show absolute wind vectors in the $\mathrm{El}$ Niño experiment. In JJA, there is an increase in upper tropospheric divergence in the east Pacific near $30^{\circ} \mathrm{S}$ under El Niño. This is associated with an eastward shift in the region of ascent near the South Pacific convergence zone (not shown) (Lachlan-Cope and Connolley 
2006), which is much weaker in austral summer. The changes to the RWS in the South Pacific sector in the El Niño experiment are also small in DJF and in the transition seasons (see also Fig. S2). Note that in DJF, larger RWS anomalies are found in the Northern Hemisphere (not shown). In contrast, there are stronger RWS anomalies in JJA under El Niño conditions. There is a strong positive RWS anomaly located at approximately $30^{\circ} \mathrm{S}, 100^{\circ}-120^{\circ} \mathrm{W}$ with a peak magnitude of $\sim 5.5 \times$ $10^{-10} \mathrm{~s}^{-2}$. There is also a weaker negative RWS anomaly located at around $30^{\circ} \mathrm{S}, 150^{\circ}-180^{\circ} \mathrm{W}$. This result is consistent with Jin and Kirtman (2009), who identified a similar seasonality in RWS anomalies in the South Pacific sector in reanalysis data and model experiments with a periodic El Niño forcing shifted in phase by 6 months. Note that the changes in RWS in the El Niño experiment are comparable in magnitude to the RWS in the control experiment (not shown). This is consistent with the changes in upper-tropospheric divergence (Figs. 7a,b), which show a strong positive anomaly at the location of the RWS anomaly in the South Pacific.

Figure 8 shows the contributions to the change in RWS in JJA from the three terms in Eq. (2): $\zeta D$ (Fig. 8a), $v_{\chi_{x}} \nabla \zeta_{x}$ (Fig. 8b), and $v_{\chi_{y}} \nabla \zeta_{y}$ (Fig. 8c). This shows that most of the change in RWS in JJA is explained by $\zeta D$, which represents the change in vorticity due to vortex stretching [see Eq. (2)]. To further decompose the change in $\zeta D$ $\left[(\zeta D)^{\prime}\right]$ into the parts associated with changes in vorticity and changes in divergence, we linearize the term as follows:

$$
(\zeta D)^{\prime}=\left(\zeta_{0}+\zeta^{\prime}\right)\left(D_{0}+D^{\prime}\right)-\zeta_{0} D_{0}
$$

where the subscript 0 denotes control experiment values and the primes denote the deviations from the control in the El Niño experiment. Multiplying out Eq. (10) gives

$$
(\zeta D)^{\prime}=\zeta_{0} D^{\prime}+\zeta^{\prime} D_{0}+\zeta^{\prime} D^{\prime} .
$$

While this provides a framework to decompose separately the contributions of changes in divergence and changes in absolute vorticity to $(\zeta D)^{\prime}$, one must bear in mind that it is nontrivial in equilibrium experiments such as these to distinguish the effects that may initiate the wave train from the changes in climatology due to the wave train itself. For example, changes in the STJ are likely to be associated with anomalous divergence while the anomalous vorticity is likely to be associated with the presence of the wave train itself. With this caveat in mind, Figs. 9a, 9b, and $9 \mathrm{c}$ show $\zeta_{0} D^{\prime}, \zeta^{\prime} D_{0}$, and $\zeta^{\prime} D^{\prime}$ for the El Niño experiment, respectively. The largest contribution to $(\zeta D)^{\prime}$ comes from the $\zeta_{0} D^{\prime}$ term. This is

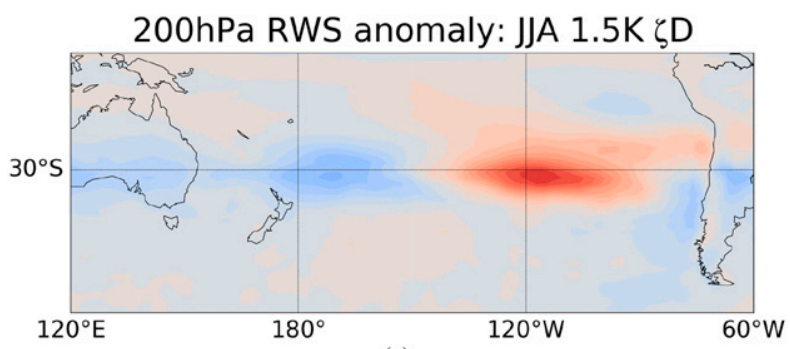

(a)

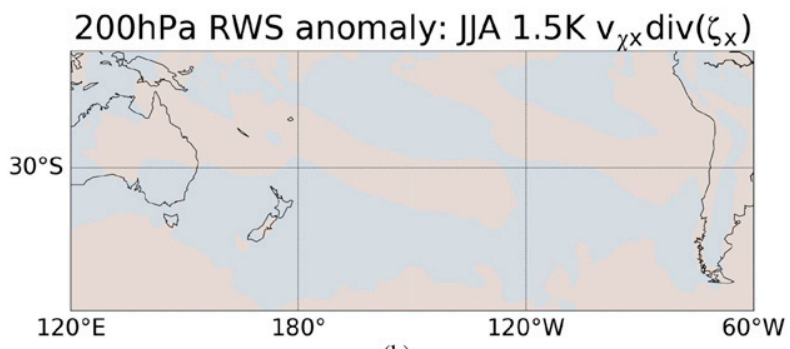

(b)

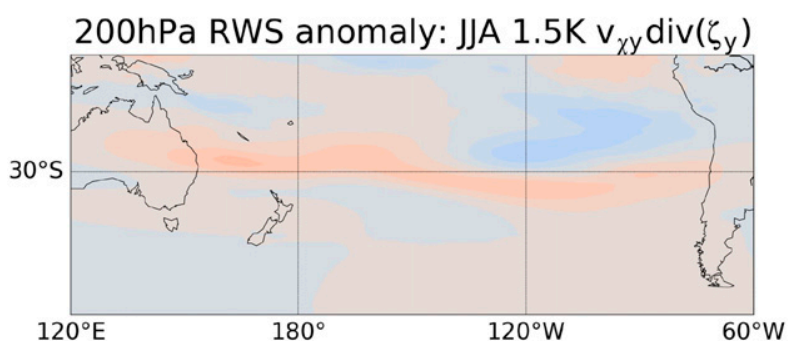

(c)

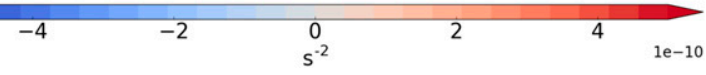

FIG. 8. Contributions of the three terms (a) $\zeta D$, (b) $v_{\chi_{x}} \nabla \zeta_{x}$, and (c) $v_{\chi_{y}} \nabla \zeta_{y}\left(\mathrm{~s}^{-2}\right)$ to the RWS anomaly in JJA in the El Niño experiment.

because in JJA the relative changes in $D$ in the South Pacific under El Niño are large compared to the relative change in $\zeta$. This is interesting as the local deep convective response along the equator (Figs. $4 a, b$ ) lies near and just east of the dateline, around $0^{\circ}, 165^{\circ} \mathrm{W}$, while the strong RWS anomaly in JJA near $30^{\circ} \mathrm{S}, 120^{\circ} \mathrm{W}$ is due to the anomalous divergence in the exit region of the anomalously strong STJ (Figs. 8a and 9a). These results are consistent with Lachlan-Cope and Connolley (2006) insofar as heating in the eastern equatorial Pacific does not generate a local deep convective response owing to the presence of climatological subsidence. Therefore owing to the special conditions in the eastern tropical Pacific, which differ from other parts of the tropics, there is minimal vorticity advection by the divergent wind. In DJF, the changes in $D$ are substantially smaller (Fig. 7a); this is consistent with the result of Jin and Kirtman (2009), who showed a strong seasonality 


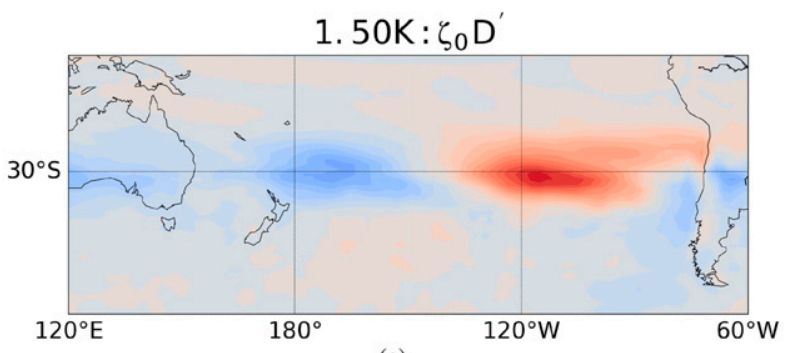

(a)

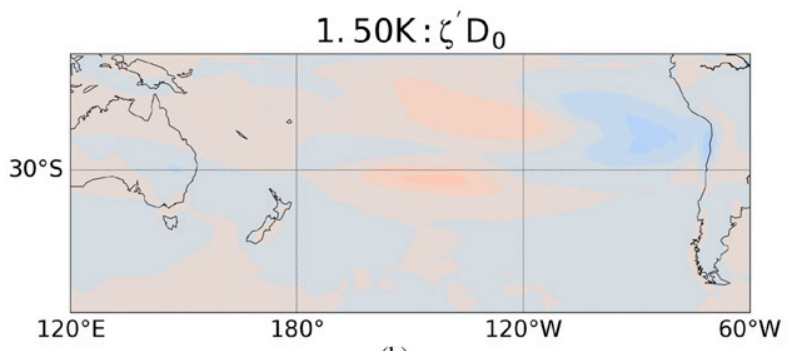

(b)

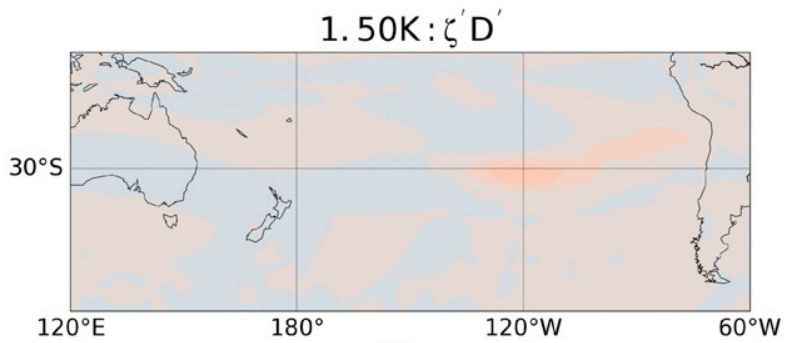

(c)

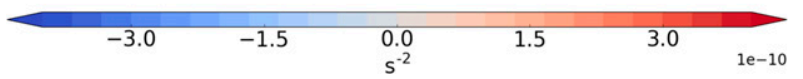

FIG. 9. Contributions of (a) $\zeta_{0} D^{\prime}$, (b) $\zeta^{\prime} D_{0}$, and (c) $\zeta^{\prime} D^{\prime}\left(\mathrm{s}^{-2}\right)$ to the $200-\mathrm{hPa} \zeta D$ anomaly in JJA in the El Niño experiment.

in upper-tropospheric divergence in the South Pacific sector in experiments forced with a periodic El Niño. There is a smaller but still significant contribution from the nonlinear term $\zeta^{\prime} D^{\prime}$, while $\zeta^{\prime} D_{0}$ makes little contribution to $(\zeta D)^{\prime}$.

While we have so far focused on seasonal mean analyses, we now show the evolution of the uppertropospheric maximum zonal winds and the RWS over the full annual cycle. Recall that the El Niño perturbation imposed here is held constant throughout the year. Figure 10a shows the latitude of the peak zonal-mean zonal wind at $200 \mathrm{hPa}$ in the Southern Hemisphere by month in the control experiment. From September to April, the latitude of the maximum zonal-mean zonal wind is at approximately $50^{\circ} \mathrm{S}$ with a rapid transition to a latitude of approximately $30^{\circ} \mathrm{S}$ between May to August. This shows the strongest upper-tropospheric zonal winds being located within the high-latitude PFJ and the lower-latitude STJ, respectively. Figure 10b shows the

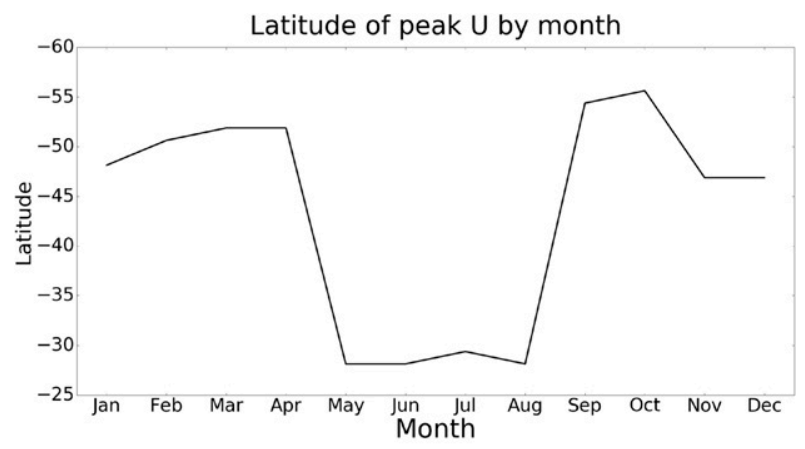

(a)

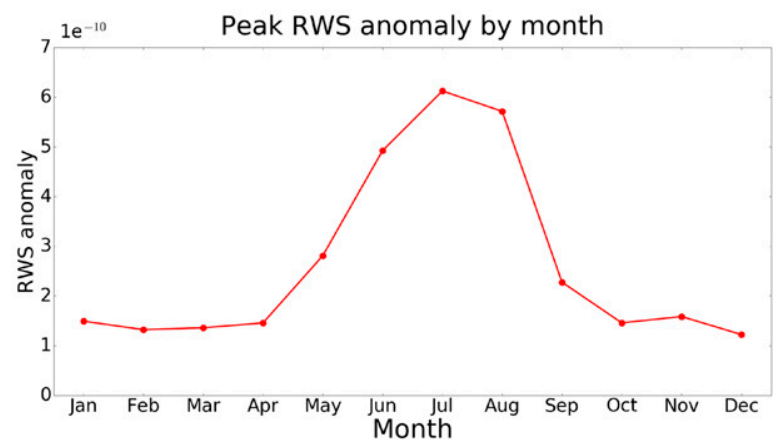

(b)

FIG. 10. (a) Latitude of peak 200-hPa zonal-mean zonal wind (Southern Hemisphere only) and (b) maximum RWS anomaly in the South Pacific sector by month in the El Niño experiment.

peak RWS anomaly in the South Pacific sector in the El Niño experiment. The maximum RWS anomaly seems to be correlated with the latitude of the maximum zonal wind. Consistent with what was seen above for the seasonal mean analysis, the RWS anomaly is strongest during May to August compared to September to April. This demonstrates the importance of the STJ in generating the RWS anomaly and is consistent with the finding that the largest contributor to the RWS anomaly comes from $\zeta^{\prime} D_{0}$.

\section{d. Rossby wave propagation by season}

The previous section established that the anomalous RWS induced by the imposed El Niño perturbation only occurs in austral winter and is small in austral summer. In this section, we will investigate using Rossby wave ray tracing the propagation characteristics for linear barotropic stationary Rossby waves in both seasons. We will also examine the anomalous wave activity flux in the El Niño experiment following Plumb (1985).

The red lines in Fig. 11 show example Rossby wave ray traces derived using Eq. (8) for DJF and JJA. The Rossby waves are initialized in both seasons approximately at the location of the strong positive RWS anomaly seen in JJA in Fig. 7b. Although the RWS anomaly is not seen in DJF, rays are initialized here to 


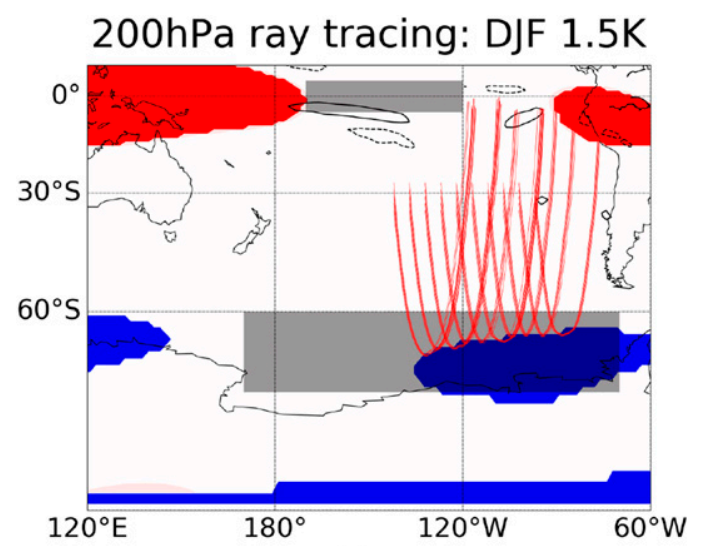

(a)

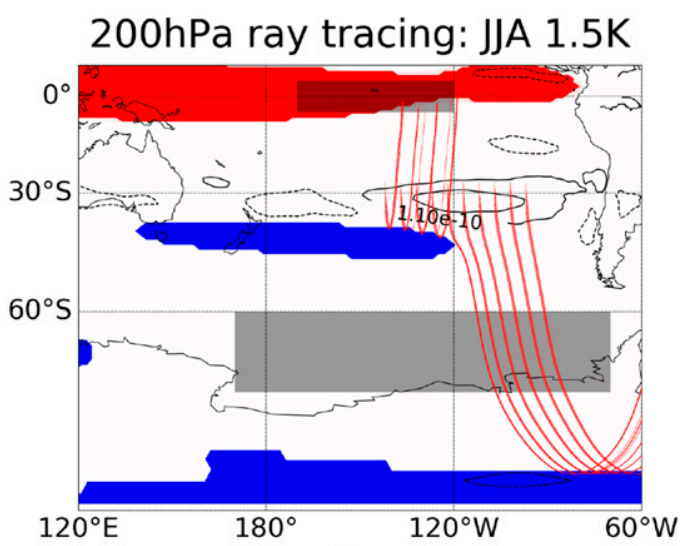

(b)

FIG. 11. Rossby wave ray tracing at $200 \mathrm{hPa}$ for the El Niño experiment for (a) DJF and (b) JJA. The rays are initialized approximately at the location of the positive RWS anomaly found in JJA in Fig. 7. The red regions indicate regions of wave evanescence (i.e., $U<0$ ), blue regions denote regions of wave reflection (i.e., $\beta^{*} / U$ $<k^{2}$ ), and white regions indicate propagation regions. The red lines are example paths taken by hypothetical Rossby waves.

enable a comparison of the relative propagation characteristics between the two seasons under a hypothetical identical wave source region. For reference, the gray shaded boxes in Fig. 11 denote the Niño-3.4 region and the ASR. The blue areas show wave reflection zones (i.e., $\beta^{*} / U<k^{2}$ ), red areas are regions of wave evanescence (i.e., $U<0$ ), and white areas are regions where wave propagation is permitted.

In JJA, the rays propagate from the RWS region to the ASR. The path taken by the rays approximately follows the PSA wave train. In DJF, the initiated Rossby wave rays are all reflected at around $60^{\circ} \mathrm{S}, 60^{\circ}-120^{\circ} \mathrm{W}$ before reaching deep into the ASR. Recall that wave reflection occurs when $\beta^{*} / U<k^{2}$. As $k$ is fixed in the examples shown in Fig. $11(k=3)$, wave reflection will occur when $\beta^{*}$ is small and/or when $U$ is large. The meridional gradient of absolute vorticity can be expressed as $\beta^{*}=\beta-U_{y y}$, where $\beta$ is the planetary vorticity and $U_{y y}$ is the acceleration of the zonal wind with respect to latitude. Figures $12 \mathrm{a}$ and $12 \mathrm{~b}$ show $U_{y y}$ in the El Niño experiment for DJF and JJA, respectively. The data was filtered using triangular truncation at wavenumber 20 to minimize small-scale artifacts from differentiation.

In JJA, there is a region of strong positive $U_{y y}$ on the equatorward and poleward flanks of the STJ $\left(\sim 20^{\circ} \mathrm{S}\right.$ and

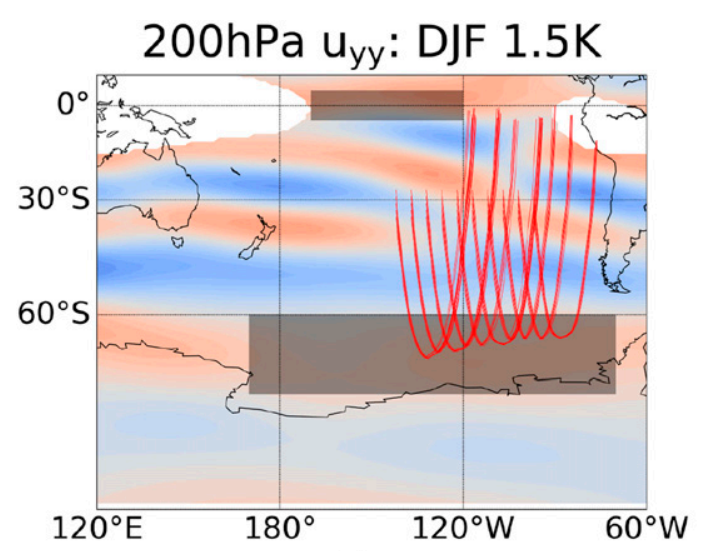

(a)

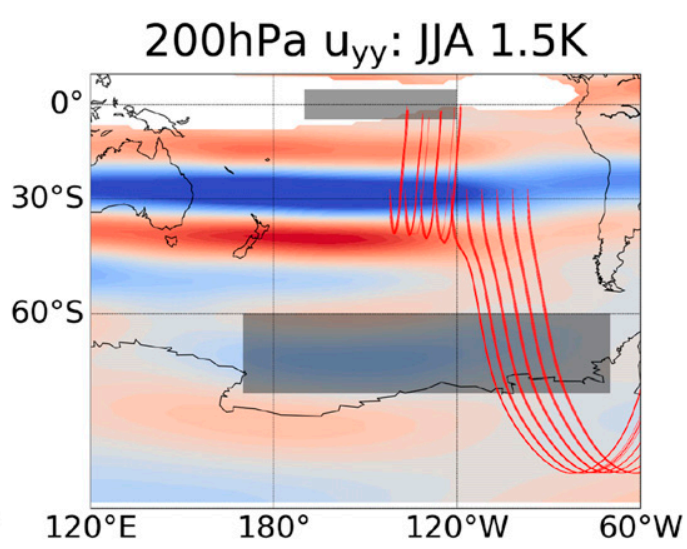

(b)

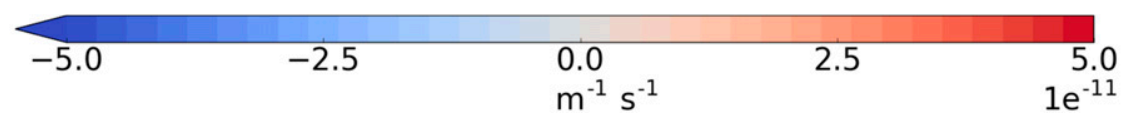

FIG. 12. Acceleration of zonal wind with respect to latitude $\left(U_{y y}\right)\left(\mathrm{m}^{-1} \mathrm{~s}^{-1}\right)$ in the El Niño experiment in (a) DJF and (b) JJA. The wave evanescence regions are whited out for reference. 


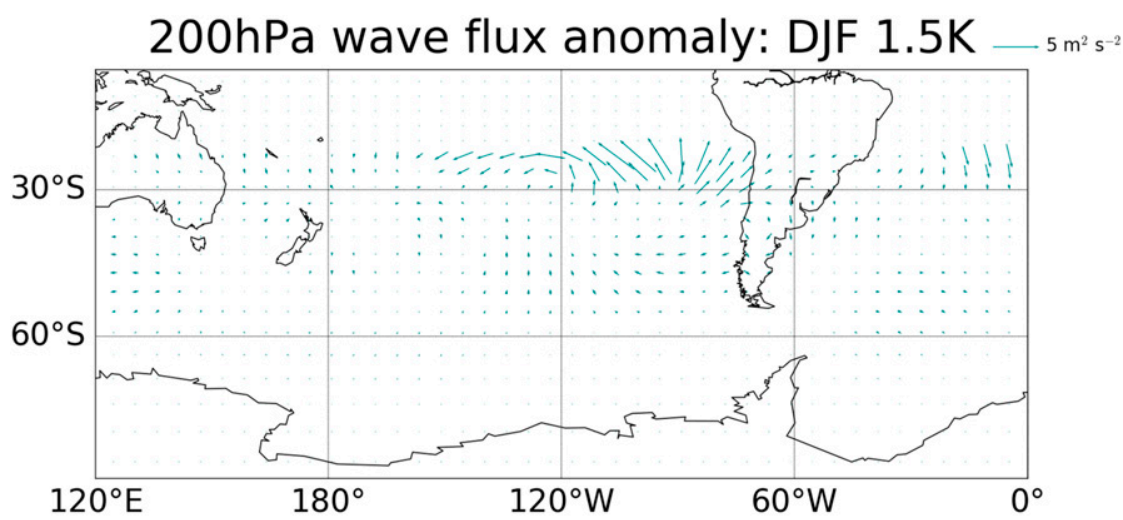

(a)

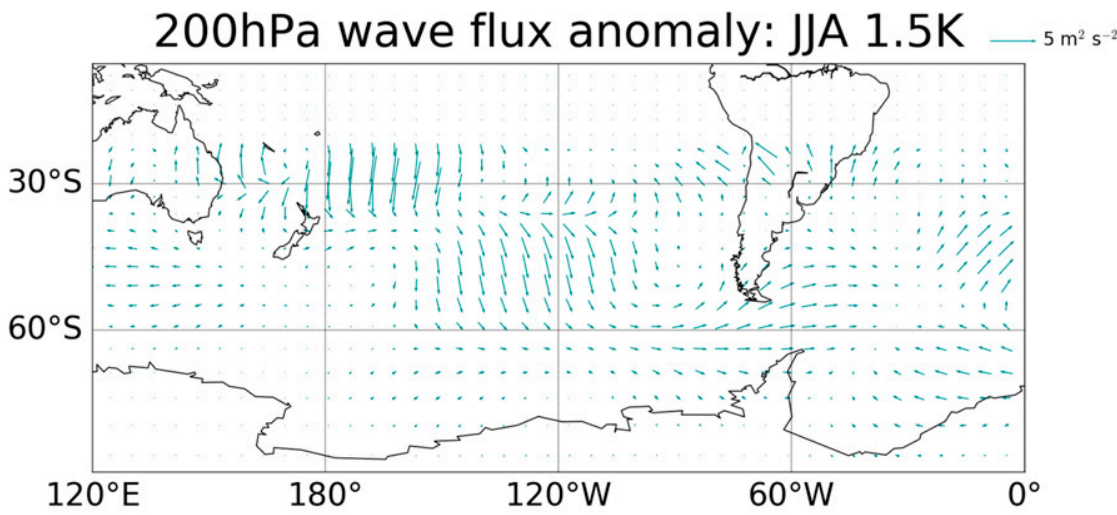

(b)

FIG. 13. Wave activity flux anomalies calculated following Plumb (1985) in the El Niño experiment in (a) DJF and (b) JJA.

$40^{\circ} \mathrm{S}$ ) and strong negative $U_{y y}$ near the jet maximum $\left(\sim 30^{\circ} \mathrm{S}\right)$. The region of strong $U_{y y}$ near $40^{\circ} \mathrm{S}$ in the central Pacific is enough to cause reflection of rays initialized west of $120^{\circ} \mathrm{W}$, but those east of this region can propagate to high latitudes. Conversely, in DJF there is a weak positive $U_{y y}$ at $\sim 60^{\circ} \mathrm{S}$ and $60^{\circ}-120^{\circ} \mathrm{W}$ that is not present in JJA. This region of weak $U_{y y}$, along with the weakening $\beta$ with increasing latitude, is enough to create a wave reflection zone north of the ASR. This local maximum in $U_{y y}$ at high latitudes is associated with the maximum in $200 \mathrm{hPa}$ zonal winds in $\mathrm{DJF}$ at $50^{\circ} \mathrm{S}$ and $100^{\circ} \mathrm{W}$ (Fig. 6c).

To complement the ray tracing analysis, Fig. 13 shows the wave activity flux anomaly in the El Niño experiment calculated from Eq. (9) (Plumb 1985). In JJA, the anomalous wave activity flux shows propagation from the subtropical South Pacific toward the ASR and then into the Weddell Sea. This approximately follows the PSA pattern and broadly agrees with the Rossby wave ray tracing shown previously. In DJF, there is a lack of anomalous wave activity flux at latitudes south of approximately $50^{\circ}-60^{\circ} \mathrm{S}$. These results broadly match the conclusions from the ray tracing analysis.

\section{Conclusions}

This study has further developed the understanding of the mechanisms responsible for the observed seasonality of the ENSO teleconnection to the Amundsen Sea region (ASR) including the Amundsen Sea low (ASL). Idealized time slice experiments were performed using the HadGEM3 model with an imposed sea surface temperature anomaly in the tropical east Pacific corresponding to a Niño-3.4 anomaly of $1.5 \mathrm{~K}$ held fixed year round. This approach is idealized, since the imposed El Niño perturbation in austral winter is larger than typically observed; however, it allows us to isolate the role of the seasonal cycle in the teleconnection to the ASR from the intrinsic seasonality in the development of ENSO seen in the real world.

The tropical response to the imposed El Niño perturbation is similar in both austral summer (DJF) and winter (JJA) seasons and comprises of an intensification 


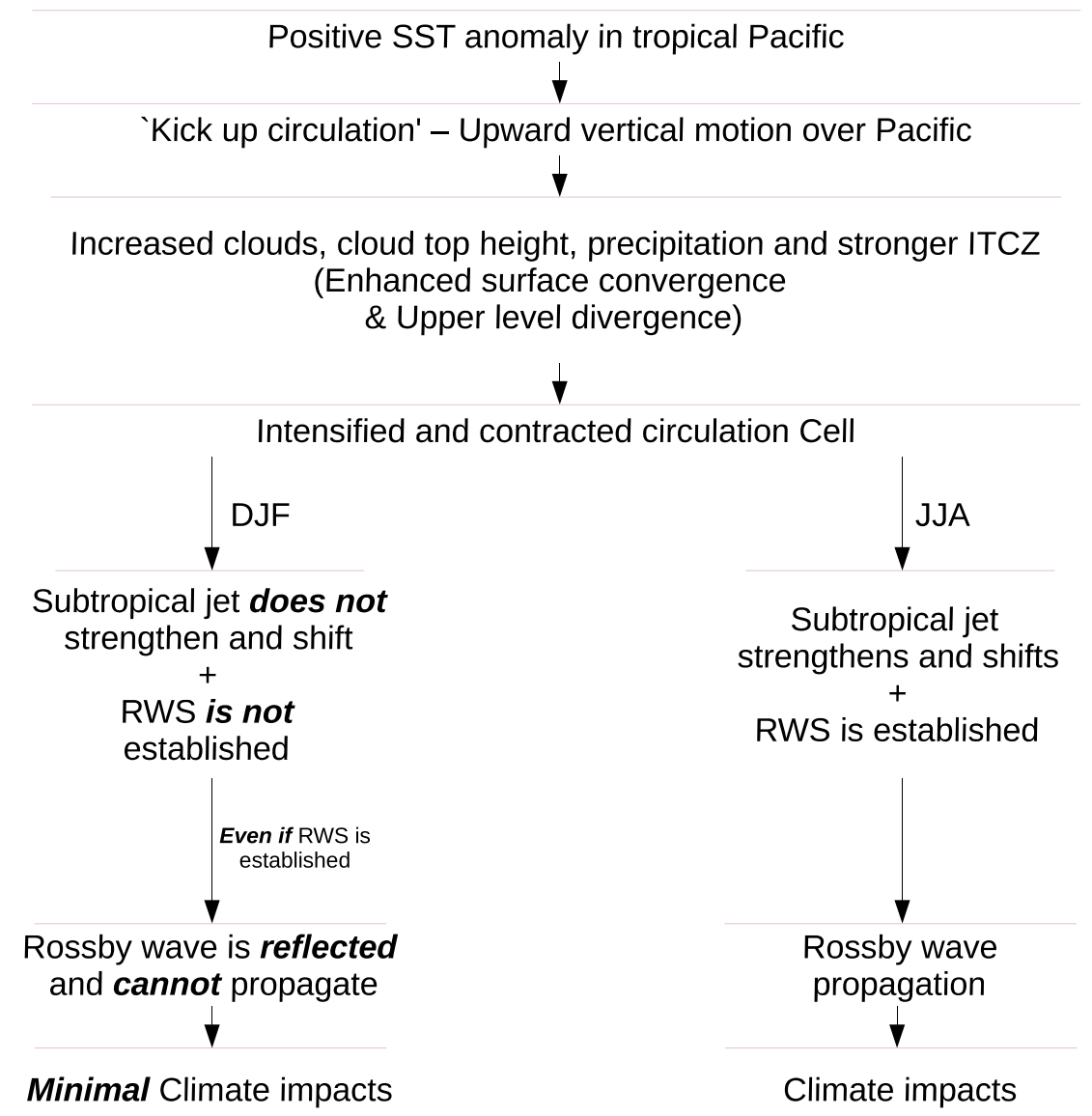

FIG. 14. Schematic flowchart summarizing the mechanisms for the El Niño teleconnection to the ASR by season discussed in this study.

and eastward shift in the region of strongest tropical convection in the Pacific as evidenced through increased tropical precipitation and decreased outgoing longwave radiation.

The structure of the Southern Hemisphere tropospheric circulation is markedly different between the two seasons. In JJA there are two distinct jets in the Southern Hemisphere, the dominant subtropical jet (STJ) and the polar front jet (PFJ) at higher latitudes. The STJ is associated with upper-tropospheric divergence and a strong vorticity gradient. Under El Niño conditions, the STJ in the Pacific sector is strengthened and shifted eastward. This leads to a strong positive RWS anomaly at $30^{\circ} \mathrm{S}, 100^{\circ}-120^{\circ} \mathrm{W}$ in JJA. However, in DJF there is only the PFJ present at around $40^{\circ}-50^{\circ} \mathrm{S}$ and the anomalous RWS at $\sim 30^{\circ} \mathrm{S}$ is absent.

Using Rossby wave ray tracing, the propagation of Rossby waves to high southern latitudes is found only to be permitted in JJA, but not in DJF. In JJA, the Rossby waves propagate from the positive RWS anomaly region at $30^{\circ} \mathrm{S}, 100^{\circ}-120^{\circ} \mathrm{W}$ toward the ASR and then to the Weddell Sea tracing the PSA pattern. However, in DJF, the Rossby waves are reflected at around $60^{\circ} \mathrm{S}$ and do not reach deep into the ASR. This reflection zone is attributed to the PFJ in the South Pacific sector in DJF. The results from ray tracing are supported by wave activity flux calculations. In JJA, there are wave fluxes emanating from the Pacific mid latitudes toward the ASR while there are minimum wave flux anomalies at high southern latitudes in DJF.

The mechanistic development of the ENSO-ASR teleconnection is summarized in Fig. 14. In conclusion, the strong ENSO teleconnection to the ASL in JJA is the result of the strong RWS anomaly from the STJ and the absence of wave evanescence or reflection zones between the Rossby wave source anomaly region and the ASR.

In the previous sections, the mechanistic differences in the teleconnection between austral summer (DJF) and austral winter (JJA) have been investigated. However, the weaker SAM-like signal in DJF remains an open question. There are still SLP anomalies in the 
ASR, albeit weaker than in JJA, even though Rossby wave generation and propagation is not favorable in the summer. One likely explanation for these weak SLP anomalies is the modulation of the SAM; see, for example, Gong et al. (2010), who found that the changing background zonal-mean flow associated with El Niño can cause wave breaking that drives negative SAM events. This can be seen from the contraction of the Hadley and Ferrell cells under El Niño conditions, which causes the STJ and the PFJ to contact equatorward. As the SAM is related to the strength and meridional movement of the PFJ (Hartmann and Lo 1998; Thompson and Wallace 2000; Lorenz and Hartmann 2001; Yang and Chang 2007; Gong et al. 2010) and associated changes in synoptic wave fluxes, this will favor a more negative phase of the SAM. A more negative SAM would cause anomalously high pressure over Antarctica in general. This fits the SAM-like SLP anomaly pattern seen in DJF.

Finally, it is important to treat these studies as an idealized investigation into the teleconnection mechanisms rather than as a definitive study of real world ENSO-ASL teleconnection. We have neglected several aspects of observed ENSO characteristics, such as its seasonal evolution. However, the controlled nature of the model experiments has enabled a detailed assessment of the mechanisms involved in ENSO-ASR teleconnection and their dependence on season, which is challenging in reanalysis datasets because of the relatively small number of El Niño events and because many characteristics including magnitude, structure and temporal evolution vary between individual events. Nevertheless, it is important to put these model results in the context of observational analyses. Lachlan-Cope and Connolley (2006) investigated the ENSO teleconnection to the Amundsen-Bellingshausen Sea in austral winter using the ERA-40 reanalysis dataset and found that the anomalous Rossby wave source occurs in areas away from the greatest SST anomalies. This is in agreement with our results generated using a global climate model. To cleanly separate the effect of the seasonal cycle on the teleconnection, we imposed a constant El Niño perturbation year round. However, a 1.5-K El Niño in JJA has only occurred once in recent history (1982) and is almost double the magnitude of most moderate-size El Niños observed in austral winter. Meanwhile, a $1.5-\mathrm{K}$ anomaly in DJF would only classify as a moderate El Niño event. Therefore, it is important to note that the response in JJA in our experiments is larger than what might be observed for a "typical" El Niño.

There are several possible extensions to this work. First, we have only explored the effects of east Pacific El
Niños. Therefore other aspects of the El Niño teleconnection, such as occasions when there is anomalous upper-level convergence and positive OLR anomalies in the western tropical Pacific, have not been explicitly investigated. Additional model experiments and Rossby wave methods could be performed to compare the ENSO-ASR teleconnection for central Pacific El Niño events (see, e.g., Ciasto et al. 2015). Second, the ENSOASR teleconnection under La Niña has not been investigated in our work. Previous studies, such as Turner et al. (2013) and Fogt et al. (2011), have found stronger (but opposite in sign) SLP changes at high southern latitudes under La Niña conditions. Further work could address the mechanisms for this response.

Acknowledgments. YYSY was supported by a Natural Environment Research Council (NERC) PhD studentship (Grant NE/K004921/1). ACM was supported by an AXA Research Fund Postdoctoral Fellowship and a NERC Independent Research Fellowship (Grant NE/M018199/1). We thank N. Luke Abraham for providing the control model setup. We are grateful to Peter Braesicke, John Pyle, Peter Haynes, Tim Woollings, John Turner, and Scott Hosking for helpful comments on this work. We thank the three anonymous reviewers whose comments improved the paper.

\section{REFERENCES}

Abram, N., R. Mulvaney, F. Vimeux, J. Steven, J. Turner, and M. H. England, 2014: Evolution of the Southern Annular Mode during the past millennium. Nat. Climate Change, 4, 564-569, https://doi.org/10.1038/nclimate2235.

Barnes, E. A., and L. Polvani, 2013: Response of the midlatitude jets, and of their variability, to increased greenhouse gases in the CMIP5 models. J. Climate, 26, 7117-7135, https://doi.org/ 10.1175/JCLI-D-12-00536.1.

Bertler, N. A. N., P. J. Barrett, P. A. Mayewski, R. L. Fogt, K. J. Kreutz, and J. Shulmeister, 2004: El Niño suppresses Antarctic warming. Geophys. Res. Lett., 31, L15207, https://doi.org/ 10.1029/2004GL020749.

Chen, B., S. R. Smith, and D. H. Bromwich, 1996: Evolution of the tropospheric split jet over the South Pacific Ocean during the 1986-89 ENSO cycle. Mon. Wea. Rev., 124, 1711-1731, https:// doi.org/10.1175/1520-0493(1996)124<1711:EOTTSJ>2.0.CO;2.

Ciasto, L. M., G. R. Simpkins, and M. H. England, 2015: Teleconnections between tropical Pacific SST anomalies and extratropical Southern Hemisphere climate. J. Climate, 28, 56-65, https://doi.org/10.1175/JCLI-D-14-00438.1.

Clem, K. R., and R. L. Fogt, 2013: Varying roles of ENSO and SAM on the Antarctic Peninsula climate in austral spring. $J$. Geophys. Res. Atmos., 118, 11481-11492, https://doi.org/ 10.1002/jgrd.50860.

, J. A. Renwick, and J. McGregor, 2017: Large-scale forcing of the Amundsen Sea low and its influence on sea ice and West Antarctic temperature. J. Climate, 30, 8405-8424, https:// doi.org/10.1175/JCLI-D-16-0891.1. 
Dee, D. P., and Coauthors, 2011: The ERA-Interim reanalysis: Configuration and performance of the data assimilation system. Quart. J. Roy. Meteor. Soc., 137, 553-597, https://doi.org/ 10.1002/qj.828.

Dima, I. M., and J. M. Wallace, 2003: On the seasonality of the Hadley cell. J. Atmos. Sci., 60, 1522-1527, https://doi.org/ 10.1175/1520-0469(2003)060<1522:OTSOTH >2.0.CO;2.

Fogt, R. L., and D. H. Bromwich, 2006: Decadal variability of the ENSO teleconnection to the high-latitude South Pacific governed by coupling with the southern annular mode. J. Climate, 19, 979-997, https://doi.org/10.1175/JCLI3671.1.

,-- , and K. M. Hines, 2011: Understanding the SAM influence on the South Pacific ENSO teleconnection. Climate Dyn., 36, 1555-1576, https://doi.org/10.1007/s00382-010-0905-0.

— A. J. Wovrosh, R. A. Langen, and I. Simmonds, 2012: The characteristic variability and connection to the underlying synoptic activity of the Amundsen-Bellingshausen Seas low. J. Geophys. Res., 117, D07111, https://doi.org/10.1029/2011JD017337.

Gallego, D., P. Ribera, R. Garcia-Herrera, E. Hernandez, and L. Gimeno, 2005: A new look for the Southern Hemisphere jet stream. Climate Dyn., 24, 607-621, https://doi.org/10.1007/ s00382-005-0006-7.

Galvin, J. F. P., 2007: The weather and climate of the tropics. Part 2-The subtropical jet streams. Weather, 62, 295-299, https:// doi.org/10.1002/wea.65.

Gill, E. A., 1980: Some simple solutions for heat-induced tropical circulation. Quart. J. Roy. Meteor. Soc., 106, 447-462, https:// doi.org/10.1002/qj.49710644905.

Gillett, N. P., and D. W. J. Thompson, 2003: Simulation of recent Southern Hemisphere climate change. Science, 302, 273-275, https://doi.org/10.1126/science.1087440.

Gong, T., S. B. Feldstein, and D. Luo, 2010: The impact of ENSO on wave breaking and southern annular mode events. J. Atmos. Sci., 67, 2854-2870, https://doi.org/10.1175/ 2010JAS3311.1.

,-- , and - , 2013: A simple GCM study on the relationship between ENSO and the southern annular mode. J. Atmos. Sci., 70, 1821-1832, https://doi.org/10.1175/JAS-D-12-0161.1.

Hartmann, D. L., and F. Lo, 1998: Wave-driven zonal flow vacillation in the Southern Hemisphere. J. Atmos. Sci., 55, 1303 1315, https://doi.org/10.1175/1520-0469(1998)055<1303: WDZFVI $>2.0 . \mathrm{CO} ; 2$.

Held, I. M., and I.-S. Kang, 1987: Barotropic models of the extratropical response to El Niño. J. Atmos. Sci., 44, 3576-3586, https://doi.org/ 10.1175/1520-0469(1987)044<3576:BMOTER $>2.0 . C O ; 2$.

Hosking, J. S., A. Orr, G. J. Marshall, J. Turner, and T. Phillips, 2013: The influence of the Amundsen-Bellingshausen Seas low on the climate of West Antarctica and its representation in coupled climate model simulations. J. Climate, 26, 6633-6648, https://doi.org/10.1175/JCLI-D-12-00813.1.

Hoskins, B. J., and D. J. Karoly, 1981: The steady linear response of a spherical atmosphere to thermal and orographic forcing. $J$. Atmos. Sci., 38, 1179-1196, https://doi.org/10.1175/15200469(1981)038<1179:TSLROA $>2.0$. CO;2.

, and T. Ambrizzi, 1993: Rossby wave propagation on a realistic longitudinally varying flow. J. Atmos. Sci, 50, 16611671, https://doi.org/10.1175/1520-0469(1993)050<1661: RWPOAR $>2.0 . \mathrm{CO} ; 2$.

Inatsu, M., and B. J. Hoskins, 2004: The zonal asymmetry of the Southern Hemisphere winter storm track. J. Climate, 17, 48824892, https://doi.org/10.1175/JCLI-3232.1.
Jin, D., and B. P. Kirtman, 2009: Why the Southern Hemisphere ENSO responses lead ENSO. J. Geophys. Res., 114, D23101, https://doi.org/10.1029/2009JD012657.

$\longrightarrow$, and - 2010: How the annual cycle affects the extratropical response to ENSO. J. Geophys. Res., 115, D06102, https:// doi.org/10.1029/2009JD012660.

Jin, F., and B. J. Hoskins, 1995: The direct response to tropical heating in a baroclinic atmosphere. J. Atmos. Sci., 52, 307319, https://doi.org/10.1175/1520-0469(1995)052<0307: TDRTTH $>2.0 . \mathrm{CO} ; 2$.

Karoly, D. J., 1989: Southern Hemisphere circulation features associated with El Niño-Southern Oscillation events. J. Climate, 2, 1239-1252, https://doi.org/10.1175/1520-0442(1989)002<1239: SHCFAW $>2.0 . \mathrm{CO} ; 2$.

_ , and B. J. Hoskins, 1982: Three-dimensional propagation of planetary waves. J. Meteor. Soc. Japan, 60, 109-123, https:// doi.org/10.2151/jmsj1965.60.1_109.

Keeble, J., P. Braesicke, N. L. Abraham, H. K. Roscoe, and J. A. Pyle, 2014: The impact of polar stratospheric ozone loss on Southern Hemisphere stratospheric circulation and climate. Atmos. Chem. Phys., 14, 13 705-13 717, https://doi.org/ 10.5194/acp-14-13705-2014.

Kreutz, K. J., P. A. Mayewski, I. I. Pittalwala, L. D. Meeker, M. S. Twickler, and S. I. Whitlow, 2000: Sea level pressure variability in the Amundsen Sea region inferred from a West Antarctic glaciochemical record. J. Geophys. Res., 105, 40474059, https://doi.org/10.1029/1999JD901069.

Lachlan-Cope, T., and W. Connolley, 2006: Teleconnections between the tropical Pacific and the Amundsen-Bellinghausens Sea: Role of the El Niño/Southern Oscillation. J. Geophys. Res., 111, D23101, https://doi.org/10.1029/2005JD006386.

- W. M. Connolley, and J. Turner, 2001: The role of the nonaxisymmetric Antarctic orography in forcing the observed pattern of variability of the Antarctic climate. Geophys. Res. Lett., 28, 4111-4114, https://doi.org/10.1029/2001GL013465.

L'Heureux, M. L., and W. J. Thompson, 2006: Observed relationships between the El Niño-Southern Oscillation and the extratropical zonal-mean circulation. J. Climate, 19, 276-287, https://doi.org/10.1175/JCLI3617.1.

Li, X., E. P. Gerber, D. M. Holland, and C. Yoo, 2015: A Rossby wave bridge from the tropical Atlantic to West Antarctica. $J$. Climate, 28, 2256-2273, https://doi.org/10.1175/JCLI-D-1400450.1.

Liu, J., X. Yuan, D. Rind, and D. G. Martinson, 2002: Mechanism study of the ENSO and southern high latitudes climate teleconnections. Geophys. Res. Lett., 29, 1679, https://doi.org/ 10.1029/2002GL015143.

Lorenz, D. J., and D. L. Hartmann, 2001: Eddy-zonal flow feedback in the Southern Hemisphere. J. Atmos. Sci., 58, 33123327, https://doi.org/10.1175/1520-0469(2001)058<3312: EZFFIT $>2.0 . \mathrm{CO} ; 2$.

Lu, J., G. Chen, and D. M. W. Frierson, 2008: Response of the zonal mean atmospheric circulation to El Niño versus global warming. J. Climate, 21, 5835-5851, https://doi.org/10.1175/ 2008JCLI2200.1.

Marshall, G. J., 2003: Trends in the southern annular mode from observations and reanalyses. J. Climate, 16, 4134-4143, https:// doi.org/10.1175/1520-0442(2003)016<4134:TITSAM >2.0.CO;2.

Plumb, R. A., 1985: On the three-dimensional propagation of stationary waves. J. Atmos. Sci., 42, 217-229, https://doi.org/ 10.1175/1520-0469(1985)042<0217:OTTDPO > 2.0.CO;2.

Raphael, M. N., and Coauthors, 2016: The Amundsen Sea low: Variability, change, and impact on Antarctic climate. Bull. 
Amer. Meteor. Soc., 97, 111-121, https://doi.org/10.1175/ BAMS-D-14-00018.1.

Rayner, N. A., D. E. Parker, E. B. Horton, C. K. Folland, L. V. Alexander, D. P. Rowell, E. C. Kent, and A. Kaplan, 2003: Global analyses of sea surface temperature, sea ice, and night marine air temperature since the late nineteenth century. J. Geophys. Res., 108, 4407, https://doi.org/10.1029/ 2002JD002670.

Sardeshmukh, P. D., and B. J. Hoskins, 1988: The generation of global rotational flow by steady idealized tropical divergence. J. Atmos. Sci., 45, 1228-1251, https://doi.org/10.1175/15200469(1988)045<1228:TGOGRF $>2.0$. CO;2.

Scaife, A. A., and Coauthors, 2017: Tropical rainfall, Rossby waves and regional winter climate predictions. Quart. J. Roy. Meteor. Soc., 143, 1-11, https://doi.org/10.1002/qj.2910.

Schneider, D. P., Y. Okumura, and D. Clara, 2012: Observed Antarctic interannual climate variability and tropical linkages. J. Climate, 25, 4048-4066, https://doi.org/10.1175/JCLI-D-1100273.1.

Simmons, A. J., J. M. Wallace, and G. W. Branstator, 1983: Barotropic wave propagation and instability, and atmospheric teleconnection patterns. J. Atmos. Sci., 40, 1363-1392, https://doi.org/ 10.1175/1520-0469(1983)040<1363:BWPAIA > 2.0.CO;2.

Thompson, D. W. J., and J. M. Wallace, 2000: Annular modes in the extratropical circulation. Part I: Month-to-month variability. J. Climate, 13, 1000-1016, https://doi.org/10.1175/15200442(2000)013<1000:AMITEC > 2.0.CO;2.

— , and S. Solomon, 2002: Interpretation of recent Southern Hemisphere climate change. Science, 296, 895-899, https:// doi.org/10.1126/science.1069270.

,-- , P. J. Kushner, M. H. England, K. M. Grise, and D. J. Karoly, 2011: Signatures of the Antarctic ozone hole in Southern Hemisphere surface climate change. Nat. Geosci., 4, 741-749, https://doi.org/10.1038/ngeo1296.

Trascasa-Castro, P., A. C. Maycock, Y. Y. S. Yiu, and J. K. Fletcher, 2019: On the linearity of the stratospheric and
Euro-Atlantic sector response to ENSO. J. Climate, https:// doi.org/10.1175/JCLI-D-18-0746.1, in press.

Turner, J., 2004: The El Niño-Southern Oscillation and Antarctica. Int. J. Climatol., 24, 1-31, https://doi.org/10.1002/joc.965.

— , and Coauthors, 2009: Non-annular atmospheric circulation change induced by stratospheric ozone depletion and its role in the recent increase of Antarctic sea ice extent. Geophys. Res. Lett., 36, L08502, https://doi.org/10.1029/2009GL037524. , T. Phillips, J. S. Hosking, G. J. Marshall, and A. Orr, 2013: The Amundsen Sea low. Int. J. Climatol., 33, 1818-1829, https://doi.org/10.1002/joc.3558.

— , J. S. Hosking, G. J. Marshall, T. Phillips, and T. J. Bracegirdle, 2016: Antarctic sea ice increase consistent with intrinsic variability of the Amundsen Sea low. Climate Dyn., 46, 2391-2402, https://doi.org/10.1007/s00382-0152708-9.

Walsh, K. J., I. Simmonds, and M. Collier, 2000: Sigma-coordinate calculation of topographically forced baroclinicity around Antarctica. Dyn. Atmos. Oceans, 33, 1-29, https://doi.org/ 10.1016/S0377-0265(00)00054-3.

Walters, D. N., and Coauthors, 2014: The Met Office Unified Model Global Atmosphere 4.0 and JULES Global Land 4.0 configurations. Geosci. Model Dev., 7, 361-386, https://doi.org/ 10.5194/gmd-7-361-2014.

Webster, P. J., 1981: Mechanisms determining the atmospheric response to sea surface temperature anomalies. J. Atmos. Sci., 38, 554-571, https://doi.org/10.1175/1520-0469(1981)038<0554: MDTART $>2.0 . \mathrm{CO} ; 2$.

Yang, X., and E. K. M. Chang, 2007: Eddy-zonal flow feedback in the Southern Hemisphere winter and summer. J. Atmos. Sci., 64, 3091-3112, https://doi.org/10.1175/JAS4005.1.

Yuan, X. J., 2004: ENSO-related impacts on Antarctic sea ice: A synthesis of phenomenon and mechanisms. Antarct. Sci., 16, 415-425, https://doi.org/10.1017/S0954102004002238. 